\title{
Business Coaching: Implementation of the Financial Performance Analysis and Social Media Improvement in Indonesian MSMEs' Restaurant
}

\author{
Ivanto Petrus Simamora ${ }^{1, *}$ Lily Sudhartio ${ }^{2}$
}

\author{
${ }^{1}$ Universitas Indonesia \\ ${ }^{2}$ Universitas Indonesia \\ *Corresponding author. Email: lily.sudhartio@gmail.com
}

\begin{abstract}
The MSMEs (Micro, Small, and Medium Enterprises) is a sector that has a significant contribution to GDP in Indonesia. However, there are many MSMEs that do not have sufficient knowledge regarding how to analyze the financial performance of their business. The next problem is that many MSMEs still not introducing their products even though they already have social media. This paper aims to assist one of the Indonesian MSME restaurants to analyze the financial performance of their business and improving marketing activities through Instagram. This research is qualitative research on business coaching methods. The business coaching method is used to find out the major problem, the actual condition, and then create solutions to overcome the major problems in the MSME. We found that the MSME had several problems after conducting external and internal analysis, such as BMC, PESTEL, Porter's Five Forces, STP, Marketing Mix 7P, interviews, and observations. Gap analysis and Pareto analysis emphasize the major problems, preparing the financial statement to analyze the financial performance and improving the social media activities through Instagram. Financial performance analysis will be very useful for MSME in deciding in the future. Improving social media activities through Instagram also implemented so that they can promote their products.
\end{abstract}

Keywords: Business Coaching, Financial Statement, Financial Performance Analysis, Instagram.

\section{INTRODUCTION}

Based on MSME data released by the Ministry of Cooperatives of the Republic of Indonesia, until 2018, the number of MSMEs in Indonesia reached 64,199,606 or an increase of $2.02 \%$ from 2017. MSMEs also contributed to employment which reached $97 \%$ in 2018. Based on MSMEs Association (Akumindo) data, MSMEs are the biggest GDP contributor, reaching 65\% or around Rp. 2,394,500,000,000.

MSMEs in Indonesia mostly do not yet have structured financial reports and do not use digital marketing optimally. This article will contain several analysis methods from the results of a series of interviews conducted on the object of research, namely the Dayum Burger MSMEs. The analysis methods used are STP, Marketing Mix, Business Model Canvas, PESTEL, Porters 5 Forces, SWOT, Gap Analysis and Pareto Analysis. From the results of this analysis, the researcher will formulate the problems faced by MSMEs. Furthermore, researchers conducted a coaching process for MSME owners and implemented solutions that were relevant to MSME problems.

Eventhough this MSME have many problems and gaps, this study will focus on solving the major problem so that the MSME can grow. The main problem of this research is analyzing the financial performance based on the data from financial statement. This research also focuses on improving digital marketing strategies through Instagram activites in order to promote their products.

Based on the description above, the objectives of this case study are: (1) analyzing the MSME financial performance based on the data from financial statement and (2) improving digital marketing strategies through Instagram activites in order to promote their products. 


\section{LITERATURE REVIEW}

\subsection{Financial Performance Analysis}

Higgins et al[1] explained that the purpose of analyzing financial statements is so that management and company owners can find out and evaluate management performance and company performance through the relationship between decisions taken in the operational field and then compared with financial performance.

Ross et al[2] argue that financial statement analysis is divided into financial ratio analysis, Du Pont analysis, and common-size analysis. In this case, the author will analyze the profitability ratios and the common-size income statement analysis[3].

\subsection{Common-Size Analysis}

Common-Size analysis generally involves data that is in financial statements, in relation to one item or basis in financial statements. The most common and frequently used items as a basis are total assets or income. Generally, this Common Size analysis is divided into 2, namely horizontal analysis of the financial position statement or balance sheet and vertical analysis of the income statement. In essence, common-size analysis creates a ratio or percentage between each item in the financial statement and the item on which it is based[4]. The common- size analysis is used by the author to measure the percentage of accounts in the income statement compared to the amount of revenue generated by the company.

A general measure of income statement describes or discloses each item in the income statement as a proportion of sales. This analysis is usually known as a vertical analysis of the designation used for company performance over time, as well as comparing the performance of all companies, industries or sectors. The formula for calculating the proportion of the vertical analysis of the income statement is[3]:

\section{Eachitem on $I$ I $\underline{S}=\%$ Total Sales}

\section{Figure 1. Common-Size Analysis Formula}

\subsection{Financial Ratio Analysis}

Financial ratio analysis is one of the tools that used to evaluate and measure the performance of a company[1]. Subramanyam[5] argues that ratio analysis is used to identify areas that require further investigation. Subramanyam also explained further that ratio analysis can identify important relationships and the basis for comparison in uncovering conditions and trends that are difficult to detect by examining the components that make up the ratio.

There are two profitability ratios to be used in this study based on company performance[5], namely Gross Profit Margin (GPM) Ratio and Net Profit Margin (NPM) Ratio. Gross Profit Margin Ratio[5] is the ratio that results from a comparison between gross income and total sales. This gross income margin can be increased by increasing the price of the product or by reducing the cost of goods manufactured. The formula for calculating the GPM ratio as follows:

\section{Gross Profit Margin Ratio= $\frac{\text { Gross Profit }}{\text { Total Sales }}$ \\ Total Sales}

Figure 2. Gross Profit Margin Formula

Net Profit Margin Ratio[5] is the ratio resulting from the comparison between net income and total income. The higher the NPM ratio value of a company, it can be said that the company is more effective or more capable of producing higher net income. In other words, this ratio is used to measure the ability of sales / revenue to generate net income for the company. The formula for calculating the NPM ratio is as follows:

$$
\text { Net Profit Margin Ratio }=\frac{\text { Net Income }}{\text { Total Sales }}
$$

Figure 3. Net Profit Margin Formula

\subsection{Social Media Marketing}

The emergence of social media networks has clearly changed the way individuals interact with family, friends, businesses and even strangers. This continued growth of social media presents opportunities and challenges for marketing teams from family businesses to large corporations. The marketing team can create and develop more sophisticated interactions with customers[6].

Clow \& Baack[6] also added that companies develop marketing campaigns through social media for various reasons, such as: (1) engage fans, (2) increase brand exposure, (3) avenue for customer interaction, (4) increase traffic, ( 5) generate leads, (6) enhance brand image, (7) improve search rankings, (8) gather customer intelligence, and (9) develop loyal fans, (9) increase sales. There are 2 reasons that are most often used by companies to develop marketing campaigns through social media, namely maintaining relationships with customers and increasing brand and product exposure to potential target customers. 
Bae and Zamrudi's[7] research analyzed the social fulfillment aspects of social media marketing and concluded that these characteristics were considered useful in satisfying consumer motivation. This study assesses motivation, beliefs, community participation, and psychological factors that place these as significant motivators of perspective and relevant social media marketing for consumers.

Kusumasondjaja's research[8] found that interactive brand posts on social media were responded to more often than informative message content. These findings highlight that Facebook performs better for interactive entertainment posts and Instagram is better suited for interactive content that combines entertainment appeal and informative messaging. Interactive posts uploaded via Facebook and Instagram received the most responses, while posts containing informative messages received the least response.

\subsection{Instagram}

Instagram is one of the fastest- growing image-based social networking sites and in 2018 it has reached 1 (one) billion active users[9]. Since its inception, Instagram has allowed users to take and upload photos, apply filters, and share photos with followers who can leave impressions and leave comments[10]. Over time, new features and formats have been incorporated into Instagram, for example the story feature and IGTV. This contributes and Instagram receives more interactions on average per post than Twitter and Facebook[11].

The motivation for customer engagement can vary[12], customer engagement, yes, or is determined by the content delivered by a brand. Stephen \& Galak[13] stated that social media is an important means of communicating with customers. Platforms like Instagram allow brands to engage directly and consumers can say through posts that capitalize on visuals and textual. A brand can reach a target consumer or large audience at a relatively low cost compared to paid media activities such as advertising. By using Instagram[14], then: (1) MSME can increase their business income, (2) add information on their Instagram profiles by adding URLs that can be clicked by Instagram users, and (3) creating advertisements via Instagram Ads.

\section{METHOD}

This research is a qualitative research through business coaching method. Researcher collect the primary data and secondary data through in depth interviews, observations, documentations, and literature studies. This business coaching consists of several stages, such as: (1) external and internal analysis, (2) SWOT analysis, TOWS, Gap Analysis, Pareto analysis, (3) action planning, (4) implementation and evaluation.

\section{RESULT AND DISCUSSION}

\subsection{Implementation of Financial Performance Analysis}

Table 1. Vertical Common-size Analysis (Jan-Feb 2020)

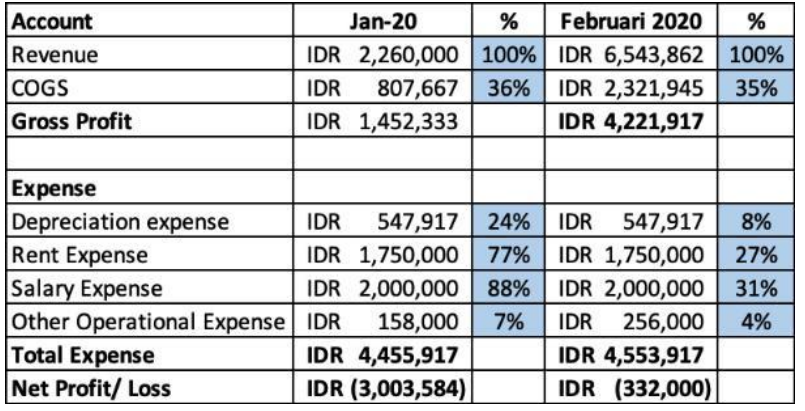

Table 2. GPM and NPM Analysis (Jan-Apr 2020)

\begin{tabular}{|l|c|c|c|c|}
\hline Ratio & Jan-20 & Feb-20 & Mar-20 & Apr-20 \\
\hline GPM & $64 \%$ & $65 \%$ & $65 \%$ & $65 \%$ \\
\hline NPM & $-133 \%$ & $-5 \%$ & $3 \%$ & $-74 \%$ \\
\hline
\end{tabular}

Based on the results of the vertical analysis of Dayum Burger's MSME profit and loss statement for January 2020, a significant portion is from employee salary expenses and rental expenses, which are $88 \%$ and $77 \%$ respectively when compared to total operating income. This indicates that the salary expenses and rental expenses of MSME in January were very high so that business income was not able to generate profits for MSMEs. On the other hand, this also affects the MSME NPM ratio value of $-133 \%$. This indicates that the business income generated by MSMEs is not able to generate profits because of the high operating expenses owned by MSME.

The author's analysis in February shows that there is a significant increase in terms of operating income. On the other hand, there was also a significant decrease in operating expenses. This also affects the value of the NPM ratio which gradually improves with a value of 5\%. This shows that in February 2020, MSME were able to operate quite well compared to the previous month.

The vertical analysis of the income statement in March shows that MSMEs are increasingly efficient in reducing operating expenses, so that they are able to produce a fairly good NPM, which increases to $3 \%$. The author's analysis in April, shows that there is a decrease in operating income and this is a concern, because this 
decrease in income results in uncontrollable operating expenses. This also resulted in the value of NPM dropping far to $74 \%$ because operating revenues were not able to generate profit margins due to high operating expenses. The author also analyzes the value of GPM which tends to be stable and this represents that the HPP of MSME products is relatively stable, but what is of concern is the relatively high operating expenses of MSMEs so that MSMEs find it difficult to generate profits.

\subsection{Social Media Improvement thorugh Instagram Activites}

The evaluation of Dayum Burger's Instagram social media improvements can be seen from the results of Instagram's insights shown in Figure 5. Insight[14] is one of the features of Instagram palikasi that allows users to see several elements of activity, such as: (1) account reached, which shows the number of Instagram accounts visiting our Instagram profile, (2) interactions, the number of interactions that occur on each content uploaded on Instagram, (3) impressions, and others.

Implementation of activity and content improvements on Instagram carried out for 1 month has obtained significant results when viewed from the results of Instagram insights for the November - early December period compared to the October - early November period. In the results of the insight in Figure 4 and Figure 5, there is an increase in the period November - December when the implementation of activity improvements and content uploads on Instagram Dayum Burger was carried out. There was an increase of $70.8 \%$ from the account reached element, which indicates that during this period, there was an increase in accounts viewing Dayum Burger Instagram profile when compared to the previous period.

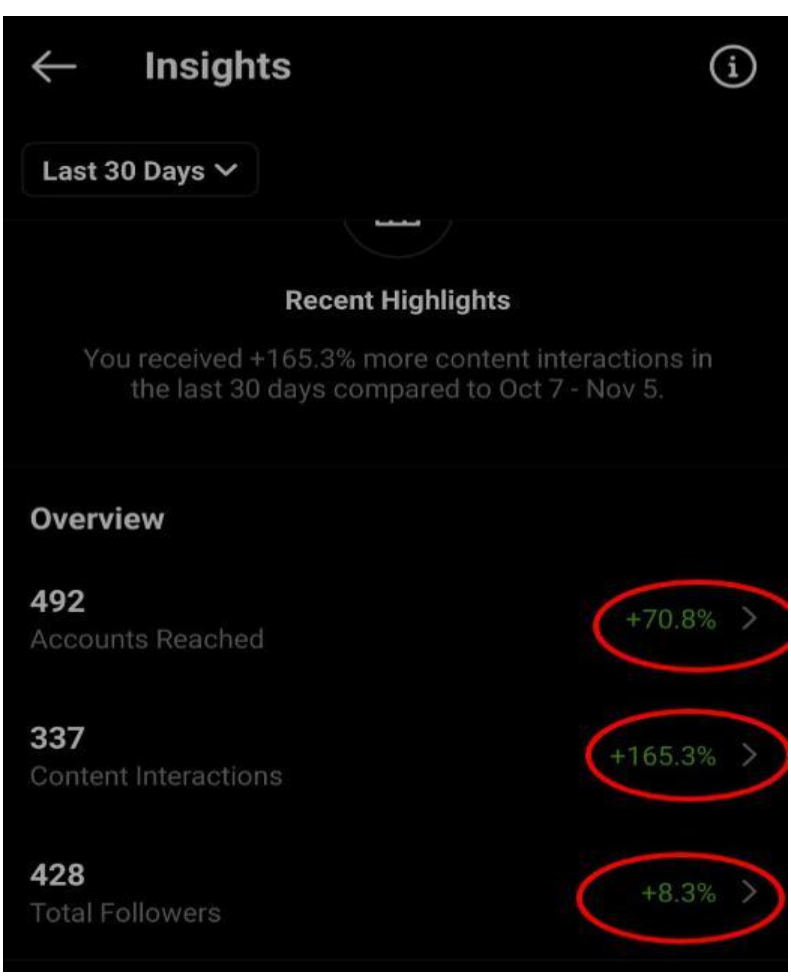

Figure 4. Instagram Activities Measurement Before Improving

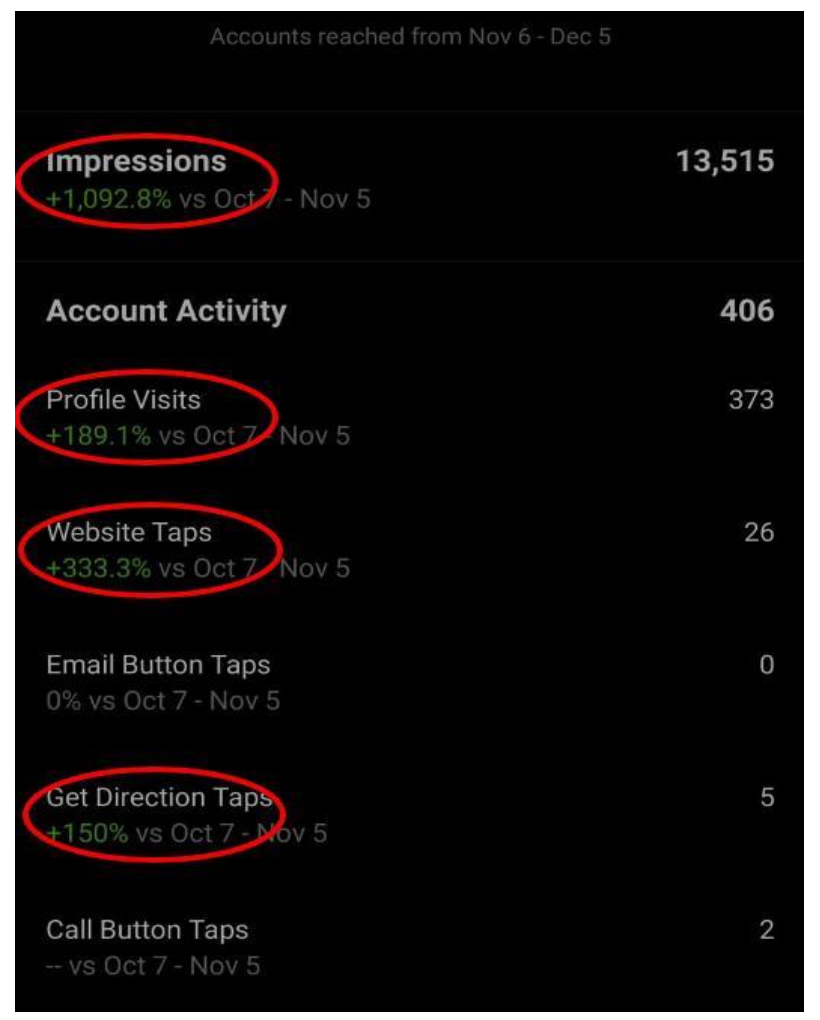

Figure 5. Instagram Activities Measurement After Improving 
The increase in element interactions also increased by $165.3 \%$. This means that during this period, the interaction of followers and other Instagram users with the content uploaded on the Dayum Burger's instagram account profile increased. The total followers on Instagram also increased in this period by $8.3 \%$.

\section{CONCLUSIONS}

This study aims to solve the MSME major problems. Based on the results of problem mapping, it is known that financial performance analysis is very necessary and has a positive effect to the owner because in the future MSME owner can make decisions based on this analysis. In addition, by providing education on how to analyze finances, in the future owners will be more able to measure the financial performance of MSME.

Improving the Instagram activities aims to attract the attention of Instagram users or followers when viewing Dayum Burger profile page. In addition, the author also provides education related tips in writing descriptions of uploaded content. After that, the author and the owner conduct an evaluation based on the results of monthly insights in the Instagram application. The results obtained are quite positive and significant, that during the improvement of activity and content on Instagram, there was an increase in account reached, followers, content interactions, and impressions. This shows that there has been an increase in the activity of Instagram users to view the Dayum Burger Instagram profile page.

\section{AUTHORS' CONTRIBUTIONS}

Ivanto Petrus Simamora contributed on the research idea, collecting data, and analyzing data. Lily Sudhartio as a supervisor to supervise the findings of this research, and reviewing this final paper.

\section{REFERENCES}

[1] R. C. Higgins, S. A. Ross, and F. Modigliani, Analysis for Financial Management Analysis for Financial Management The McGrawHill/Irwin Series in Finance, Insurance, and Real Estate. 1928.

[2] S. a Ross, Westerfield, Jordan, and Roberts, Corporate Finance, $\quad 8^{\text {th }}$ Edition,"McGraw -Hill Ryerson, 2013.
[3] D. E. Kieso, J. J. Weygandt, and T. D. Warfield, Intermediate Accounting $17^{\text {th }}$ Edition. 2019.

[4] T. R. Robinson, H. van Greuning, E. Henry, and M. A. Broihahn, International Financial Statement. 2009.

[5] K. R. Subramanyam and J. J. Wild, Financial Statement Analysis Eleventh Edition. 2014.

[6] K. E. Clow and D. Baack, Integrated advertising, promotion \&amp; marketing communications. 2018.

[7] M. F. Y. Zamrudi and B. Il-Hyun, "Challenge of social media marketing \& effective strategies to engage more customers: Selected retailer case study," Int. J. Bus. Soc., 2018.

[8] S. Kusumasondjaja, "The roles of message appeals and orientation on social media brand communication effectiveness: An evidence from Indonesia," Asia Pacific J. Mark. Logist., 2018, doi: 10.1108/APJML-10-20170267.

[9] Statistica, "Number of monthly active Instagram users from January 2013 to June 2018 (in millions)," Statistica, 2018.

[10] D. H. Kim, N. K. Seely, and J. H. Jung, "Do you prefer, Pinterest or Instagram? The role of image-sharing SNSs and self-monitoring in enhancing ad effectiveness," Comput Human Behav., 2017, doi: 10.1016/j.chb.2017.01.022.

[11] L. V. Casaló, C. Flavián, and S. Ibáñez Sánchez, "THE RELEVANCE OF CREATIVITY AND EMOTIONS IN ENGAGING USERS ON INSTAGRAM," Glob. Fash. Manag. Conf., 2018, doi: 10.15444/gmc2018.01.01.04. 
[12] J. Berger, "Word of mouth and interpersonal communication: A review and directions for future research," Journal of Consumer Psychology. 2014, doi: 10.1016/j.jcps.2014.05.002.

[13] A. T. Stephen and J. Galak, "The effects of traditional and social earned media on sales: A study of a microlending marketplace," $J$. Mark. Res., 2012, doi: 10.1509/jmr.09.0401.

[14] J. Miles, Instagram Power - Build Your Brand and Reach More Customers with the Power of Pictures. 2014. 